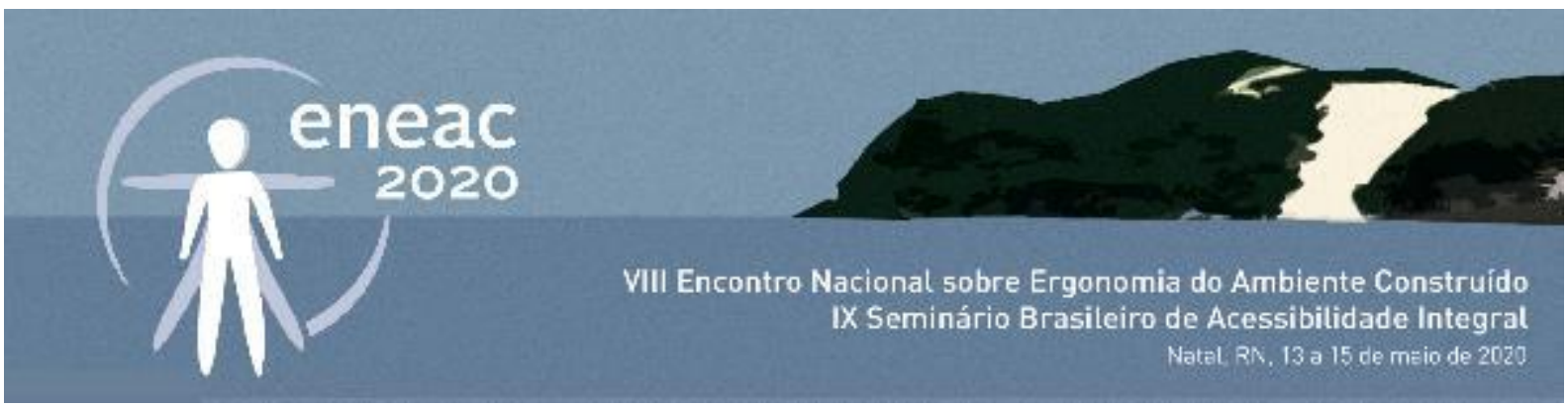

\title{
Avaliação das condições de acessibilidade das calçadas da área central de São Paulo do Potengi/RN
}

\author{
Accessibility conditions assessment of sidewalks in central area of \\ São Paulo do Potengi / RN
}

PETTERSON MICHEL DANTAS

Mestre, IFRN, petterson.dantas@ifrn.edu.br

EMILY JORDANA MOURA DE MACEDO

Estudante de curso técnico integrado de nível médio, IFRN, jordanamacedo44@gmail.com

BÁRBARA MAYARA DE LIMA ARAÚJO

Estudante de curso técnico integrado de nível médio, IFRN, barbaradopt94@gmail.com

\section{RESUMO}

Acessibilidade urbana é uma temática imprescindível para o desenvolvimento de qualquer cidade e não seria diferente para São Paulo do Potengi, município localizado no interior do Rio Grande do Norte. Considerando a calçada como elemento primordial para a circulação nas cidades, nesta pesquisa foram avaliadas suas condições de acessibilidade na área central de São Paulo do Potengi. Para isso, foi utilizado como instrumento um quadro de avaliação com os itens baseados nas normas brasileiras de acessibilidade. Como resultado, a pesquisa apontou que a maior parte dos problemas de acessibilidade encontrados estão ligados ao tipo de pavimentação empregado nas calçadas, à ausência ou instalação inadequada de piso tátil de alerta, à má conservação do passeio público e à ausência ou execução inadequada de rebaixamentos de calçadas. Verificou-se a existência de algumas tentativas de tornar o local mais acessível, todavia elas são carentes de embasamento técnico. Nesse sentido, o trabalho anseia despertar reflexões, não só na esfera acadêmica, mas também nos gestores e na sociedade, para que assim possa haver alguma mudança de perspectiva nas futuras intervenções no espaço público da cidade.

PALAVRAS-CHAVE: Acessibilidade, espaço público, calçadas, São Paulo do Potengi.

\section{ABSTRACT}

Urban accessibility is essential theme for the development of any city and are no different for São Paulo do Potengi, a municipality located in the interior of Rio Grande do Norte. Considering sidewalks as a key element for circulation, on this research were evaluated the accessibility conditions in the central area of the locality. For that, an evaluation framework with items based on Brazilian accessibility standards was used as an instrument. As a result, the survey pointed out that most of the accessibility 


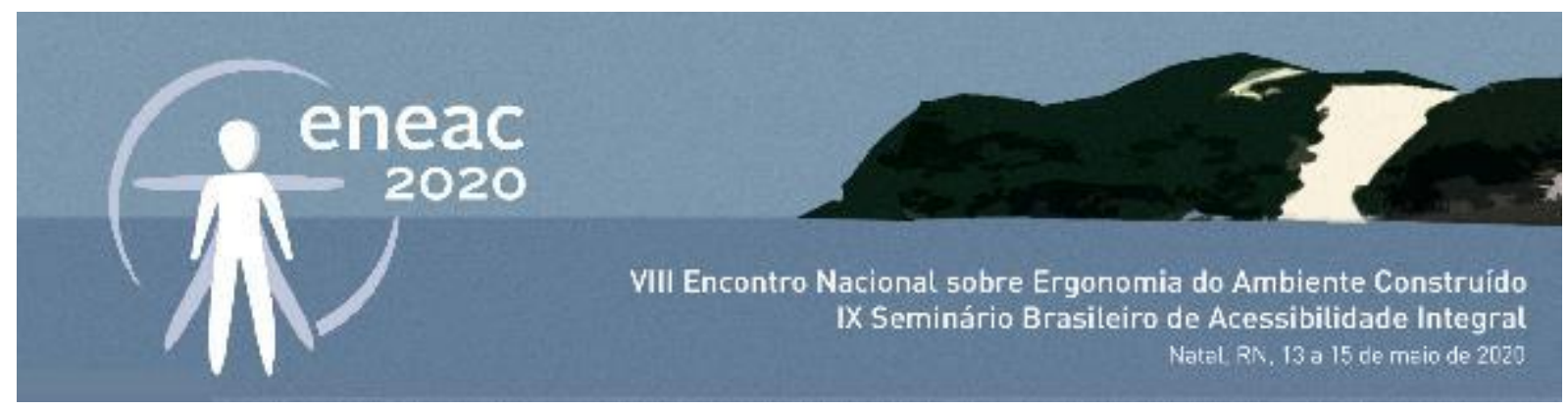

problems encountered, are associated with the type of paving used on the sidewalks, a lack or inadequate installation of the tactile warning floor, a poor maintenance of the public sidewalk and the lack or inadequate execution of ramp sidewalks. It was found that there are some attempts to make the place more accessible, however they are lacking in technical basis. In this sense, this work intends to promote reflections, not only in the academic sphere, but also in managers and in society, to may be some change of perspective in the next changes in the public space of the city.

KEYWORDS: Accessibility, public space, sidewalks, São Paulo do Potengi.

\section{INTRODUÇÃO}

O deslocamento de pedestres é forma de locomoção mais comum do mundo e constitui um direito básico humano. Quando as pessoas caminham pela cidade, entram em contato direto com o ambiente ao redor, favorecendo atividades sociais e comerciais. Uma cidade que valoriza os pedestres deve possuir uma rede de mobilidade, com calçadas, travessias seguras, acesso direto ao transporte público de qualidade, ao comércio e aos serviços.

As calçadas são parte integrante do cotidiano da população em qualquer cidade, seja ela considerada grande ou pequena. Contudo, torná-la um espaço que possibilite independência, conforto e segurança ainda é um desafio de muitas cidades brasileiras, ainda mais quando, segundo dados do Instituto Brasileiro de Geografia e Estatística (IBGE, 2010), 45,6 milhões de pessoas possuem alguma deficiência sensorial ou de locomoção permanente.

No Brasil, a NBR 9050 (ABNT, 2015) estabelece parâmetros de acessibilidade para que as edificações, mobiliário, espaços e equipamentos urbanos possam ser utilizados por pessoas com deficiência ou com mobilidade reduzida.

Visando levantar dados sobre as condições de acessibilidade no espaço público de cidades de pequeno porte do Rio Grande do Norte, este trabalho se propõe a avaliar as calçadas da área central de São Paulo do Potengi. O estudo é parte dos resultados de um projeto de pesquisa desenvolvido com alunos do Curso Técnico Integrado em Edificações do Campus São Paulo do Potengi do Instituto Federal de Educação Ciência e Tecnologia do Rio Grande do Norte (IFRN). A pesquisa desenvolvida abrangeu as cidades de São Paulo do Potengi, Lagoa de Velhos e Ruy Barbosa - local de residência dos alunos participantes - sendo neste trabalho apresentados apenas os resultados para o município de São Paulo do Potengi (SPP), que está localizado a $71 \mathrm{~km}$ de Natal, a capital do estado do Rio Grande do Norte (Figura 1).

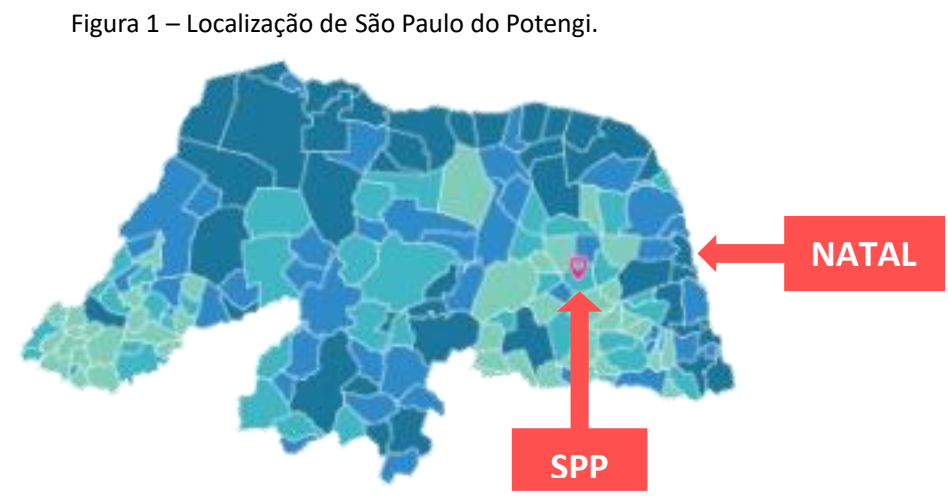






Fonte: IBGE, modificado pelos Autores.

Atualmente, de acordo com a estimativa realizada pelo Instituto Brasileiro de Geografia e Estatística (IBGE) no ano 2019, sua população é de 17.579 habitantes. É considerado o maior município da Região Potengi em população e possui área territorial de $240.425 \mathrm{~km}^{2}$. No campus IFRN-SPP, são atendidos alunos de várias cidades da região, que se qualificam nos cursos técnicos de Edificações, Meio Ambiente e Informática e no curso superior de Matemática. Especificamente no Curso para formação de Técnicos em Edificações, o conteúdo Acessibilidade é trabalhado na disciplina de Desenho Arquitetônico, explorando as normas e legislação vigentes e os parâmetros técnicos para projetos de calçadas, travessias, guias rebaixadas, estacionamentos, acessos e circulações, além de outros itens referentes ao uso das edificações.

Assim sendo, o desenvolvimento da pesquisa teve como primeiro resultado a oportunidade de os participantes consolidarem o conhecimento adquirido a partir do contato com problemas da sua realidade. Neste sentido, a pesquisa também se torna um princípio educativo, permitindo ao aluno refletir sobre como a infraestrutura das cidades pode contribuir com a circulação segura e autônoma de todos os seus cidadãos.

No plano da investigação científica, este trabalho apresenta duas contribuições. A primeira consiste na divulgação do instrumento de avaliação para condições de acessibilidade de calçadas produzido durante o desenvolvimento do projeto de pesquisa e já aplicado às cidades de São Paulo do Potengi, Lagoa de Velhos e Ruy Barbosa. A segunda consiste nos dados levantados para a cidade de São Paulo do Potengi, o que permite visualizar um panorama das condições de acessibilidade de sua área central e seus pontos críticos.

Nessa perspectiva, espera-se que os resultados apresentados no final do trabalho estimulem o debate acerca das condições de acessibilidade nas cidades de pequeno porte e subsidiem futuras pesquisas e trabalhos técnicos para melhorias da infraestrutura urbana, entendendo, também, que uma calçada acessível não se destina apenas às pessoas com deficiência, mas a todos que querem transitar com segurança e conforto pelo espaço público.

\section{REFERENCIAL TEÓRICO}

A mobilidade dos pedestres é essencial para a vitalidade das cidades, permitindo atividades comerciais e sociais, entre outras. Para Meotti, Tarouco e Tonetto (2019), a importância da calçada aumenta quando se entende que durante $o$ ato de caminhar a pessoa utiliza menos recursos e afeta o meio ambiente menos do que qualquer outra forma de transporte. Para Gehl (2015), a dimensão humana deve ser o foco da busca por cidades vivas, seguras, sustentáveis e saudáveis. Ainda segundo o autor, é necessária uma intervenção política unificada na cidade para que os moradores se sintam convidados a caminhar, em conexão com suas atividades cotidianas.

Existem vários aspectos a serem considerados para que uma cidade se torne amigável ao pedestre. A existência de sombra e abrigos, por exemplo, incentiva as pessoas a caminharem mesmo em dias de chuva ou muito quentes. Contudo, a condição mais básica para que pedestres possam ocupar os espaços públicos e aproveitar todo seu potencial é a existência de calçadas acessíveis. 


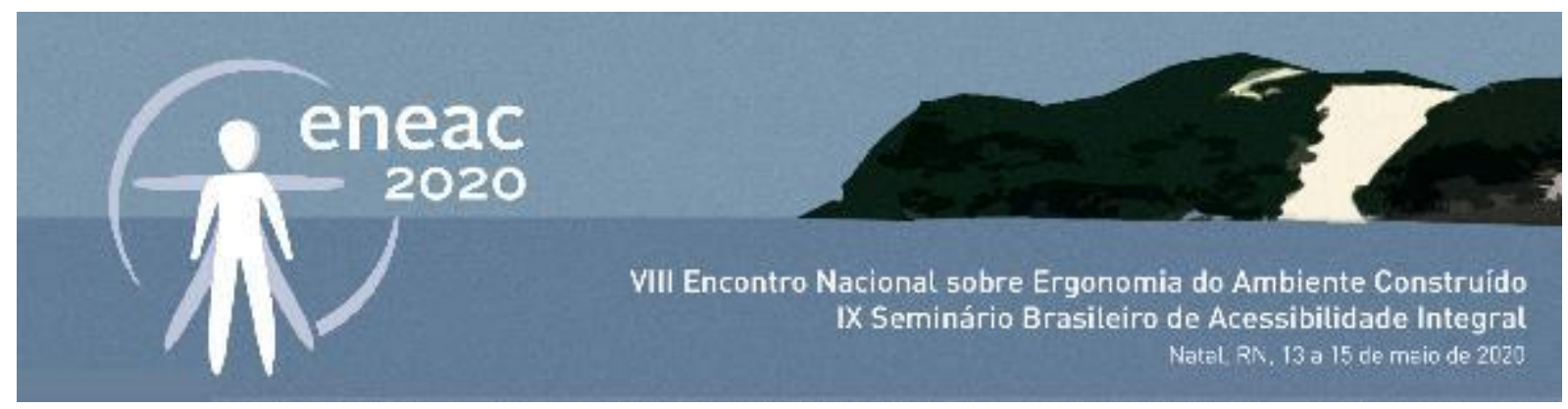

A NBR 9050 (ABNT, 2015) define calçada como parte da via, normalmente segregada e em nível diferente, não destinada à circulação de veículos, reservada ao trânsito de pedestres e, quando possível, à implantação de mobiliário, sinalização, vegetação, placas de sinalização e outros fins.

De acordo com a Lei 13.146, o Estatuto da Pessoa com Deficiência, (BRASIL, 2015), entende-se por acessibilidade a possibilidade e condição para utilização, com segurança e autonomia, de espaços, mobiliários, equipamentos urbanos, edificações, transportes, informação e comunicação, por pessoa com deficiência ou com mobilidade reduzida.

Calçadas acessíveis são aquelas adequadamente dimensionadas, livres de barreias urbanísticas e conectadas umas às outras. Entende-se por barreira urbanística, qualquer obstáculo que limite ou impeça a participação social da pessoa e sua liberdade de movimento, entre outros, nas vias e nos espaços públicos e privados abertos ao público ou de uso coletivo (BRASIL, 2015). Calçadas acessíveis permitem que pessoas com deficiência ou com mobilidade reduzida usufruam da cidade, mas notadamente também contribuem para que idosos, pessoas com carrinhos de bebês e grupos em geral circulem com conforto no espaço público.

A acessibilidade no espaço público é um tema constante nos estudos da cidade em vários países, visando a composição de uma infraestrutura urbana segura para os espaços já constituídos e para os que ainda serão projetados. Uma pesquisa semelhante à proposta neste trabalho foi desenvolvida por Caldeira, Silva e Nunes (2017), em um estudo para o turismo acessível na cidade histórica portuguesa de Guimarães. Os autores analisaram as condições que um percurso turístico recomendado para o Centro Histórico de Guimarães oferece ao turista com mobilidade reduzida. Para isso, elaboraram uma análise multicritério, baseada na avaliação de parâmetros, como declives, tipos de pisos, largura do passeio, existência de rebaixamentos, existência de barreiras e tipos de tráfego existentes na via.

Outro trabalho desenvolvido que visa estudar as condições de acessibilidade de calçadas foi realizado por Guimarães, Cunha e Santos (2015) para a área central da cidade de Goiânia, Goiás. Os autores criaram um quadro de avaliação com nove parâmetros de acessibilidade para calçadas, dividiram a área estudada em quadras e realizaram uma avaliação qualitativa, classificando as quadras, para cada parâmetro, como Nenhuma não conformidade; até 2 não conformidades; 3 ou mais não conformidades; Impossibilidade de avaliação.

Embora a participação dos usuários em trabalhos de avaliação da infraestrutura urbana das cidades possa ser utilizada, os trabalhos estudados focaram na avaliação técnica, que se desenvolve a partir da comparação da realidade com parâmetros técnicos de acessibilidade. Além dos elementos de acessibilidade, existem outros aspectos que podem ser estudados para incentivar a circulação de pedestres nas calçadas, como o uso de vegetação e mobiliário urbano, a relação das edificações com a calçada, a garantia de condições de segurança e a diversidade de experiências dispostas ao pedestre. Esses aspectos, contudo, não fazem parte do escopo deste trabalho, que semelhante ao referencial teórico estudado, se propões a uma avaliação técnica baseada nas normas de acessibilidade. Com este tipo de avaliação pretende-se caracterizar a realidade encontrada e posteriormente realizar uma comparação objetiva com as demais cidades da região de São Paulo do Potengi. 


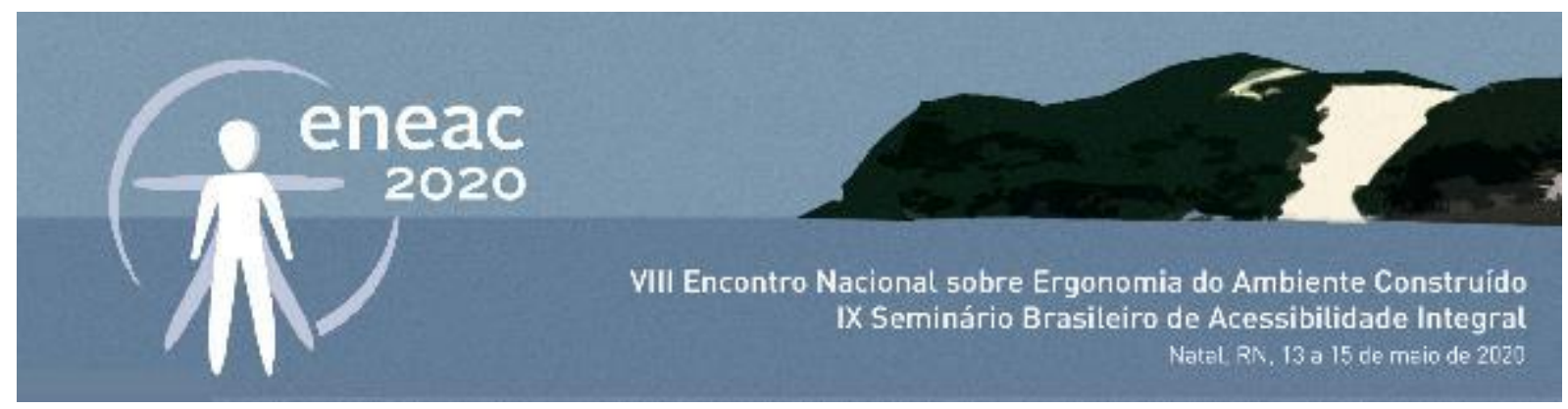

\section{METODOLOGIA}

A pesquisa neste trabalho caracteriza-se, quanto aos seus procedimentos, como estudo de caso, e quanto à natureza de sua abordagem, como uma pesquisa qualitativa. Foi desenvolvida a partir de levantamentos em campo e análise de dados com base nas normas técnicas e legislação brasileira sobre acessibilidade. Sua metodologia foi definida no projeto de pesquisa desenvolvido no IFRN-SPP mencionado anteriormente e sua realização foi segmentada em quatro etapas.

a) Primeira etapa: estudo de trabalhos semelhantes, normas e legislação sobre acessibilidade

A pesquisa foi iniciada com o aprofundamento do tema acessibilidade em calçadas, tendo como respaldo o estudo de trabalhos semelhantes, além de normas e legislações sobre acessibilidade. A bibliografia foi composta por pesquisas realizadas por Caldeira, Silva e Nunes (2017) e Guimarães, Cunha e Santos (2015). Além disso, fazem parte do referencial teórico as normas NBR 9050 (ABNT, 2015) e NBR 16537 (ABNT, 2016), que tratam, respectivamente, sobre acessibilidade nas edificações, mobiliário, espaços e equipamentos urbanos e a sinalização tátil no piso. Também foram estudadas as leis 13.146/2015 - Lei Brasileira de Inclusão da Pessoa com Deficiência, Lei 10.098/2000 Estabelece normas gerais e critérios básicos para a promoção da acessibilidade das pessoas portadoras de deficiência ou com mobilidade reduzida, e dá outras providências e a Lei 10.741/2003 - Estatuto do idoso.

O resultado desta etapa foi a definição do quadro de avaliação que resume os parâmetros de acessibilidade que tratam especificamente do dimensionamento, ocupação das faixas e pavimentação das calçadas, aplicação de piso tátil para pessoas com deficiência visual, rebaixamentos e travessias para pedestres, extraídos da NBR 9050 (ABNT, 2015) e a NBR 16537 (ABNT, 2016).

b) Segunda etapa: delimitação da área central da cidade

Para a segunda etapa, delimitou-se o trecho da área central da cidade a ser estudada. Esta delimitação se baseou na identificação e localização dos estabelecimentos e instituições públicas e coletivas, como a prefeitura, o cartório, a igreja matriz e os bancos, que geralmente se situam nos centros das pequenas cidades. Após traçar uma poligonal que englobasse esses imóveis, optou-se por estudar a área dividindo-se por calçadas. A amostragem das condições de acessibilidade das calçadas foi limitada à área central da cidade, pelo fato dessas áreas serem utilizadas pelo maior número de moradores e porque são onde normalmente ocorreram os maiores investimentos em infraestrutura urbana.

Para identificação das calçadas no quadro de avaliação, definiu-se uma forma de nomeá-las (figura 2), composta por três caracteres, considerando a divisão por quadras e sua localização em relação a dois eixos imaginários que dividem a área em quatro partes: Norte, Sul, Leste e Oeste.

Figura 2: Esquema de nomeação de calçadas.

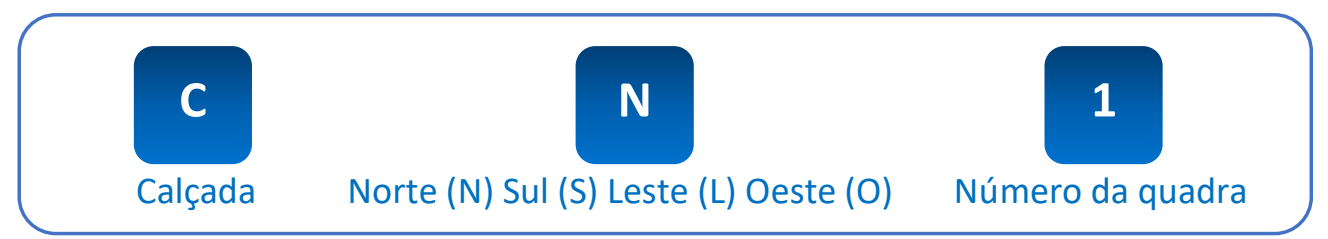




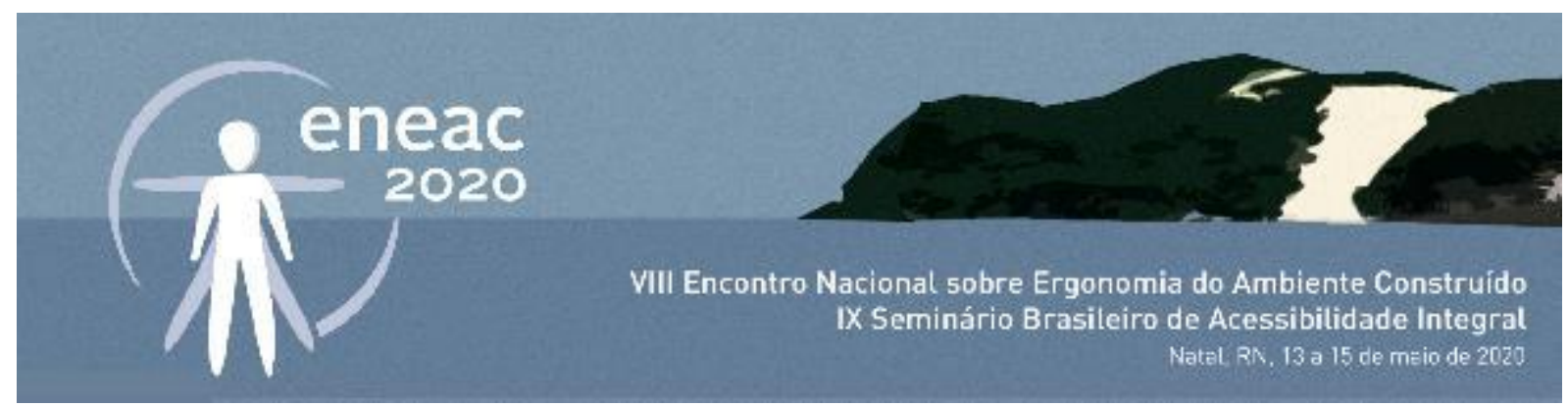

Fonte: Os Autores.

c) Terceira etapa: verificação in loco da realidade estudada

Neste segmento, realizou-se uma visita ao local de estudo, a fim de identificar in loco a situação das calçadas. Foram realizados registros fotográficos com auxílio de câmera fotográfica de smartphone e medições com o uso de trena. A coleta foi realizada pelos autores deste trabalho no mês de julho de 2019.

d) Quarta etapa: Análise dos dados levantados

Por fim, na última etapa realizou-se a análise do material levantado, tendo como suporte o instrumento de avaliação definido em etapa anterior. Foram feitas correspondências entre os elementos encontrados no trecho de estudo e os parâmetros técnicos presentes no quadro estruturado a partir da revisão bibliográfica. Desse modo, os resultados diagnosticaram a presença de inconformidades que, segundo a definição dada pela Lei da Pessoa com Deficiência (Lei $n^{\circ}$ 13.146/2015), são classificadas como barreiras. O resultado desta etapa é mostrado em um quadro de avaliação de calçadas na seção resultados e discussões.

\section{RESULTADOS E DISCUSSÕES}

A área definida para desenvolvimento da pesquisa está compreendida entre as ruas Bento Urbano, General Dantas e São José, espaço onde se localiza a Igreja Matriz, Casa de Monsenhor Expedito, Cartório, Praça de Monsenhor Expedito, Bancos e a Prefeitura Municipal (Figura 3). Além de abranger esses estabelecimentos e instituições de interesse coletivo, nesta região estão presentes lojas, feira pública e residências.

Figura 3: Definição da área a ser estudada em São Paulo do Potengi.

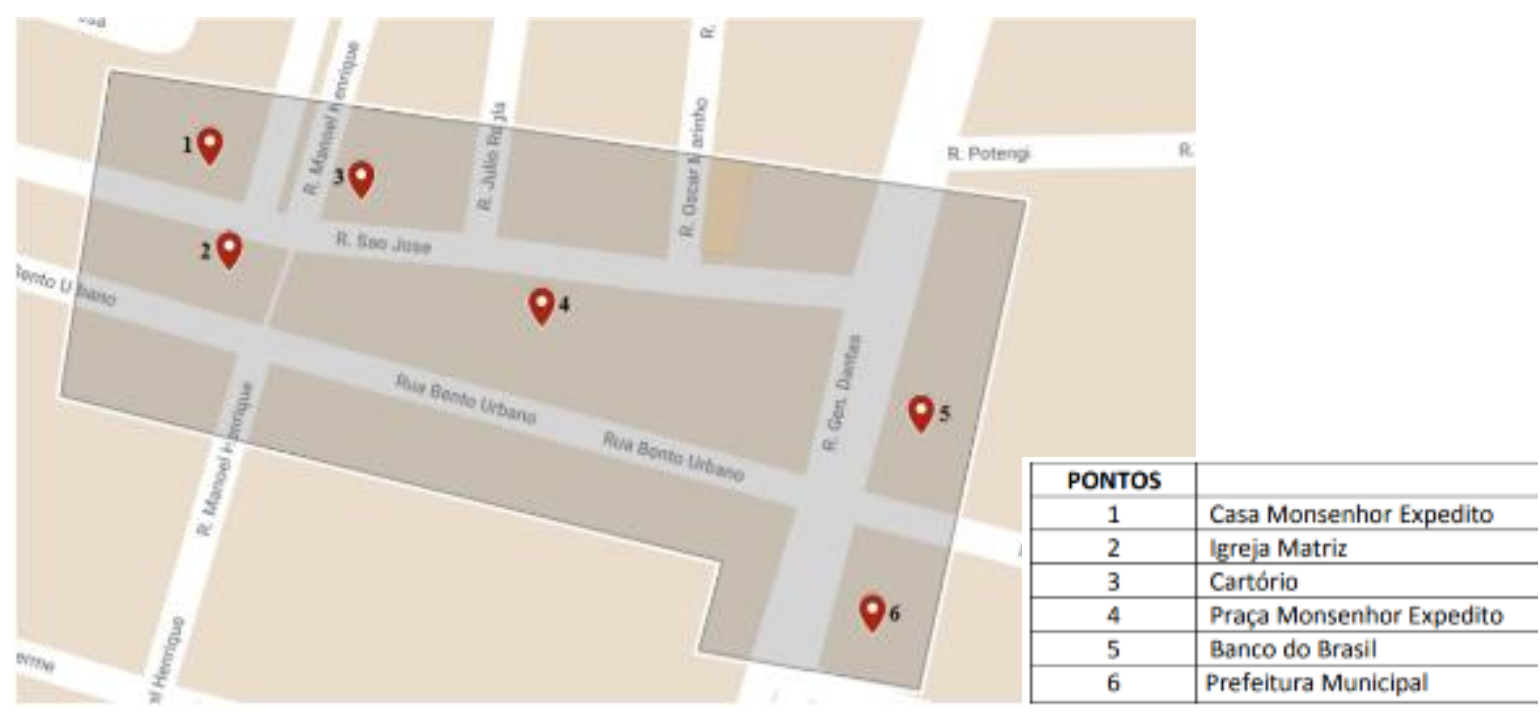




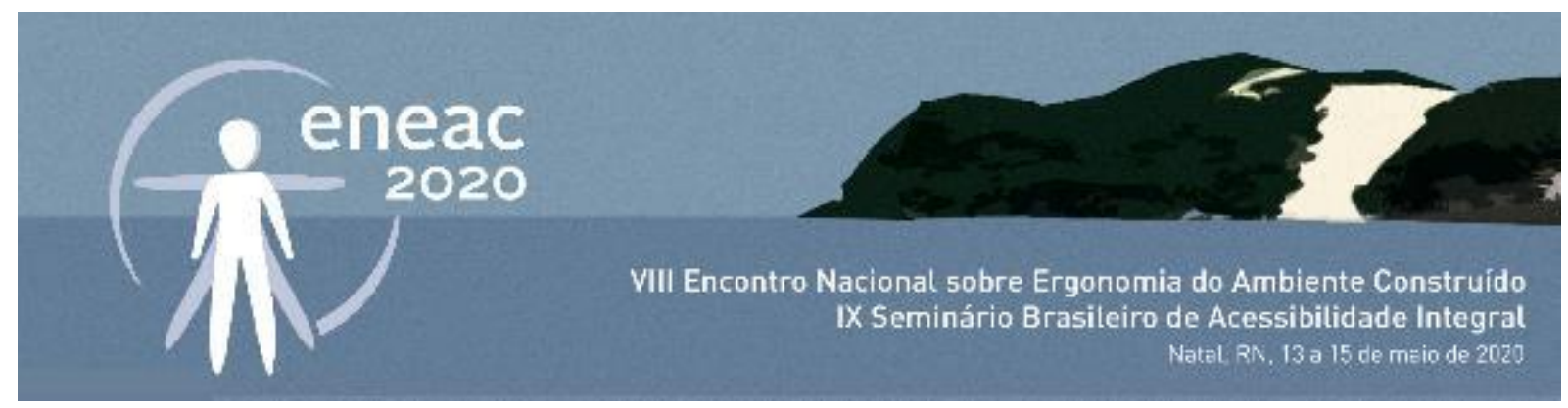

Fonte: Os Autores, sobre base do Google Maps.

Com a delimitação da área a ser estudada, as calçadas foram nomeadas utilizando-se o esquema definido na metodologia. Dessa forma, foram identificadas para avaliação as calçadas Norte 1, 2, 3 e 4; Leste 1, 2 e 3; Sul 1 e 2 (Figura 4).

Figura 4: Identificação das calçadas estudadas.

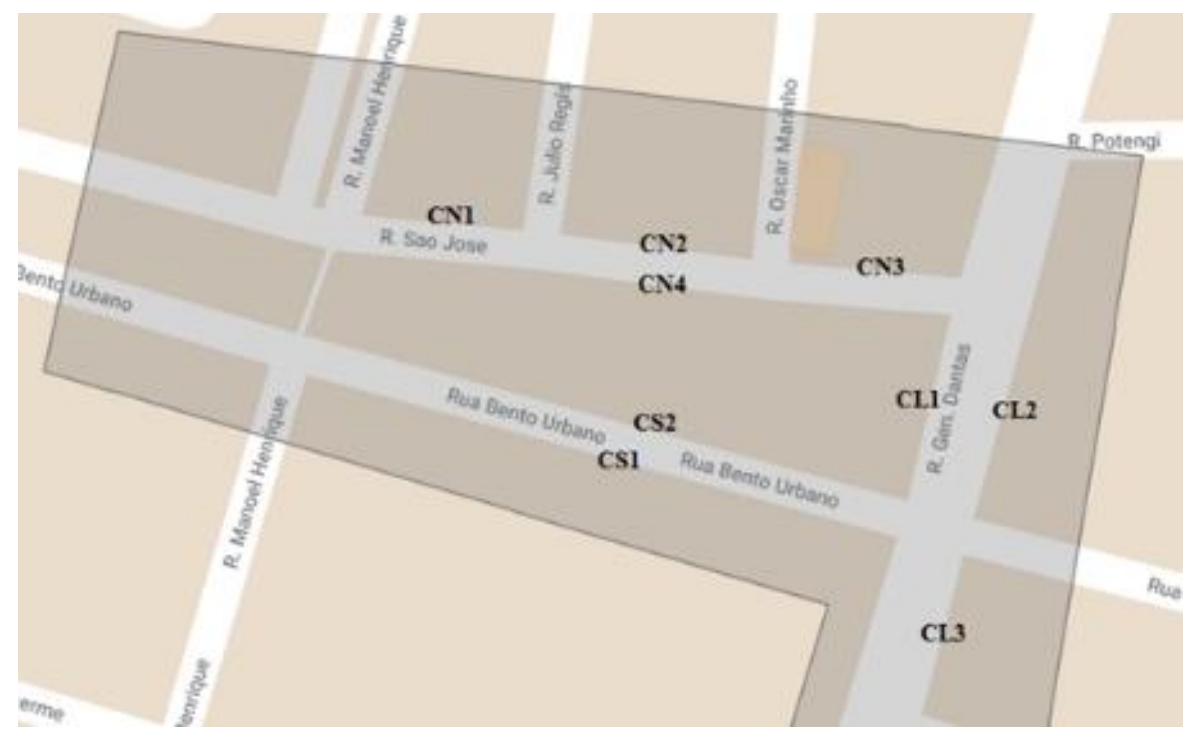

Fonte: Os autores, sobre base do Google Maps.

Após a realização da visita ao local e o estudo da situação registrada, foi realizada a classificação das inconformidades encontradas, cuja síntese é apresentada no Quadro 1. Na primeira coluna do quadro estão definidos os parâmetros analisados e na primeira linha estão identificadas as calçadas analisadas. $O$ preenchimento com a cor verde indica que a calçada atende integralmente ao referencial normativo do parâmetro estudado, a amarela indica o atendimento parcial (acima de 50\%, mas sem atendimento total) e a cor vermelha o não atendimento ou atendimento inferior a $50 \%$ das possibilidades das calçadas. A cor azul foi utilizada para situações de neutralidade, quando o parâmetro não se aplica à calçada por algum motivo.

Quadro 1: Síntese da avaliação das condições de acessibilidade.

\begin{tabular}{l|l|l|l|l|l|l|l|l|l}
\hline \multirow{2}{*}{ ITENS AVALIADOS } & \multicolumn{7}{c}{ CÓDIGO DAS CALÇADAS } \\
\cline { 2 - 9 } & CN1 & CN2 & CN3 & CN4 & CS1 & CS2 & CL1 & CL2 & CL3 \\
\hline $\begin{array}{l}\text { Continuidade das } \\
\text { calçadas entre lotes }\end{array}$ & & & & & & & & \\
\hline Largura da faixa livre & & & & & & & & \\
\hline
\end{tabular}



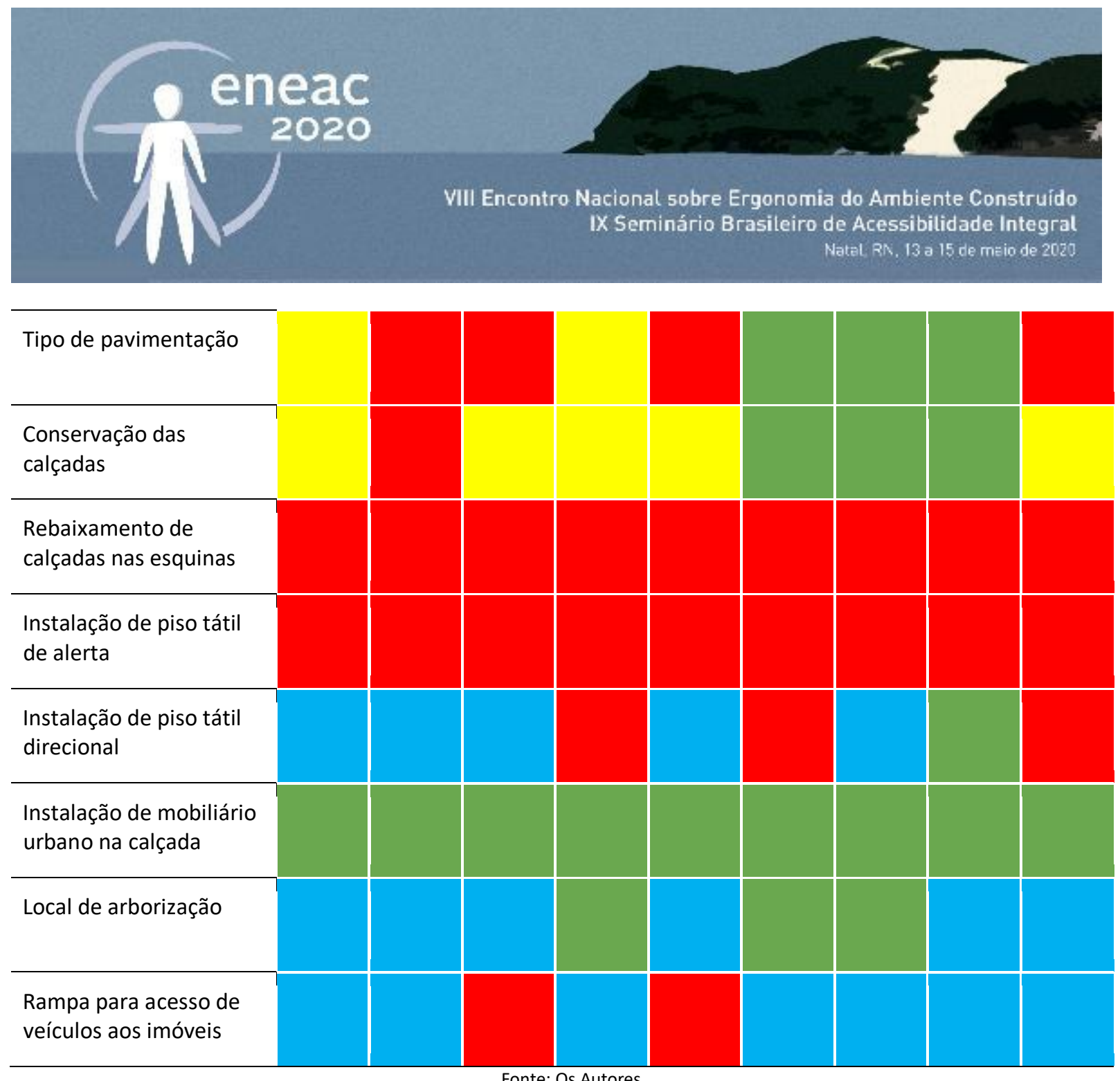

Fonte: Os Autores.

Observando-se o Quadro 1, pode-se perceber que a maior ocorrência de problemas foi no tipo de pavimentação, conservação, rebaixamento das calçadas e instalação de piso tátil de alerta. Quanto ao tipo de pavimentação das calçadas, todos os trechos analisados, exceto a Calçada Sul 2, Calçada Leste 1 e Calçada Leste 2 , apresentaram revestimentos impróprios, sendo derrapantes ou trepidantes ou com contrastes tridimensionais, como mostra a Figura 5.

Figura 5: (A) Revestimento de calçada escorregadio - CS1; (B) Revestimento com contrastes tridimensionais - CN2.



(A)

(B) 


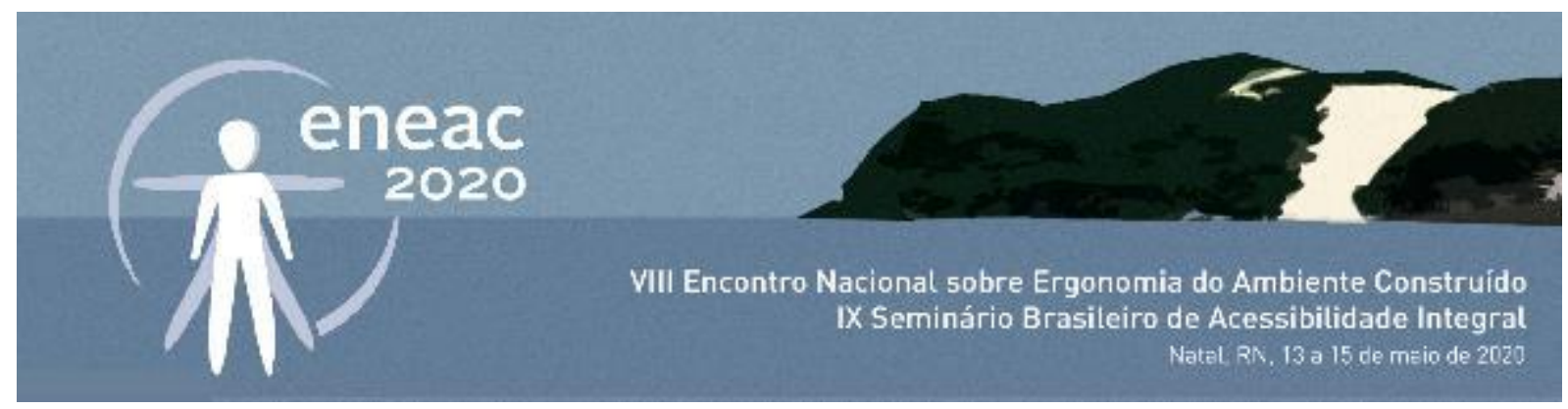

Fonte: Os Autores.

No que diz respeito à conservação dos passeios, observou-se que praticamente em todos os trechos analisados existem não conformidades, isto é, as condições de pavimentação apresentaram problemas na regularidade e na continuidade do piso, revestimentos desprendidos, mudanças de nível e buracos, como mostra a Figura 6.

Figura 6: (A) Conservação comprometida e (B) Revestimentos desprendidos.

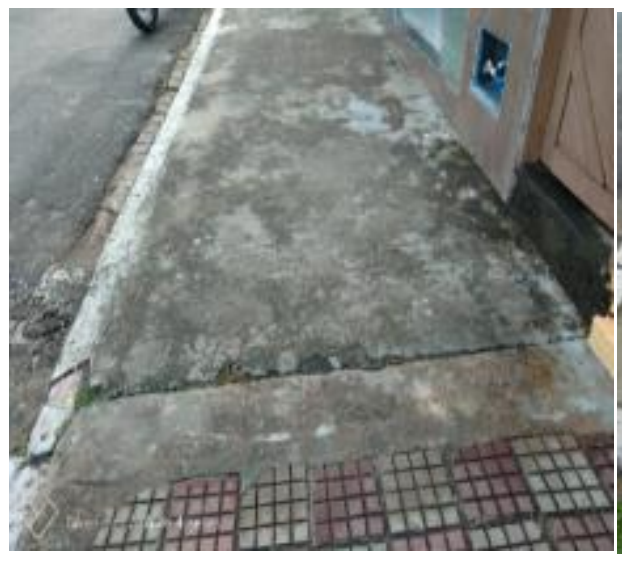

(A)

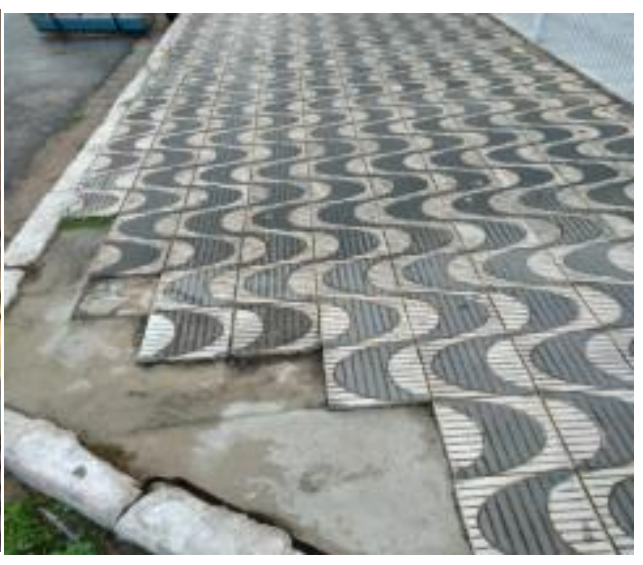

(B)

Fonte: Os Autores.

Com relação ao rebaixamento de calçadas, a grande maioria das esquinas não apresenta rebaixamentos. Foram identificadas algumas tentativas de criação de rampas, em alguns casos inclusive tentando seguir o desenho do rebaixamento do tipo trapezoidal apresentado na NBR 9050 (ABNT, 2015), contudo sem seguir os parâmetros de largura mínima de 1,50 metros e de inclinação máxima de $8,33 \%$. Além disso, a maioria dessas rampas estava em condições precárias de pavimentação, perdendo assim a sua funcionalidade e não atendendo aos requisitos de acessibilidade (Figura 7).

Figura 7: (A) Rampa irregular sem conservação - CS2; (B) Rebaixamento sem conservação com inclinação maior que 8,33\% - CN4; (C) Faixa de pedestre sem rebaixamento e com obstáculo edificado obstruindo a passagem - CS1.

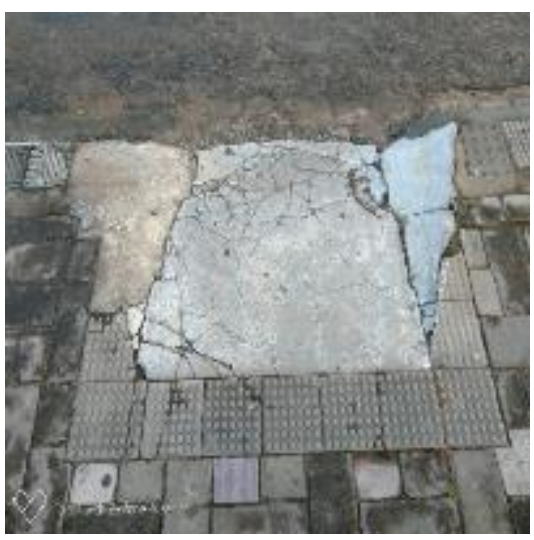

(A)

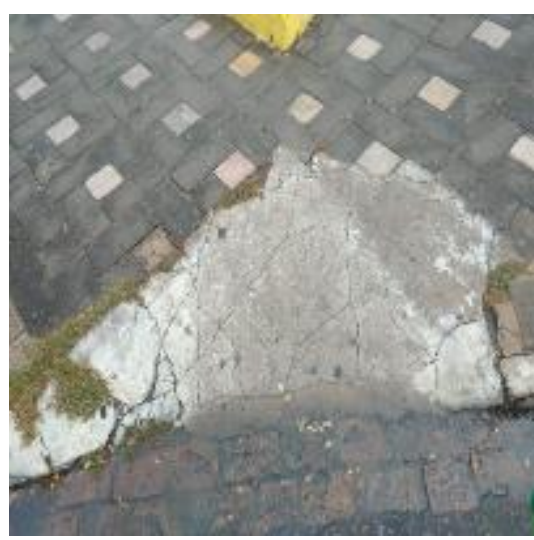

(B)

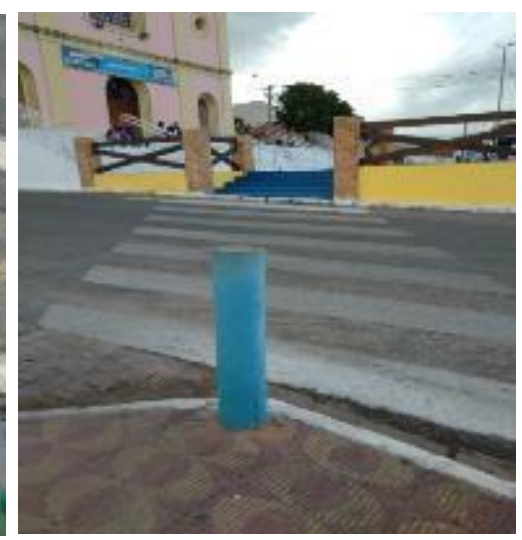

(C)

Fonte: Os Autores. 


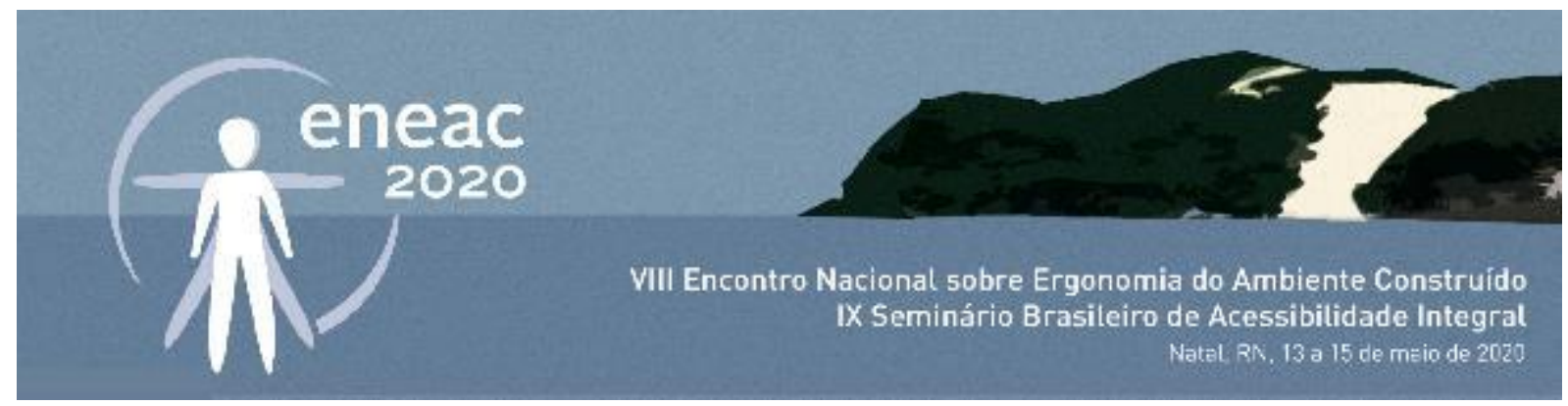

Todas as calçadas estudadas atendem ao requisito de largura da faixa livre. Em geral, as calçadas da área central de São Paulo do Potengi são completamente pavimentadas e não há distinção entre faixas de serviço, faixa livre e de acesso. A menor dimensão encontrada para as calçadas da área foi de 2,30m, o que é superior largura mínima de 1,20m estabelecida pela NBR 9050 (ABNT, 2015). A Figura 8 (B) detalha a medida da Calçada Sul 1 (CS1), uma das mais movimentadas da área. A medida registrada para sua largura foi de $2,35 \mathrm{~m}$.

Figura 8: (A) Largura da calçada - CS1; (B) Detalhe da largura da Calçada Sul 1.

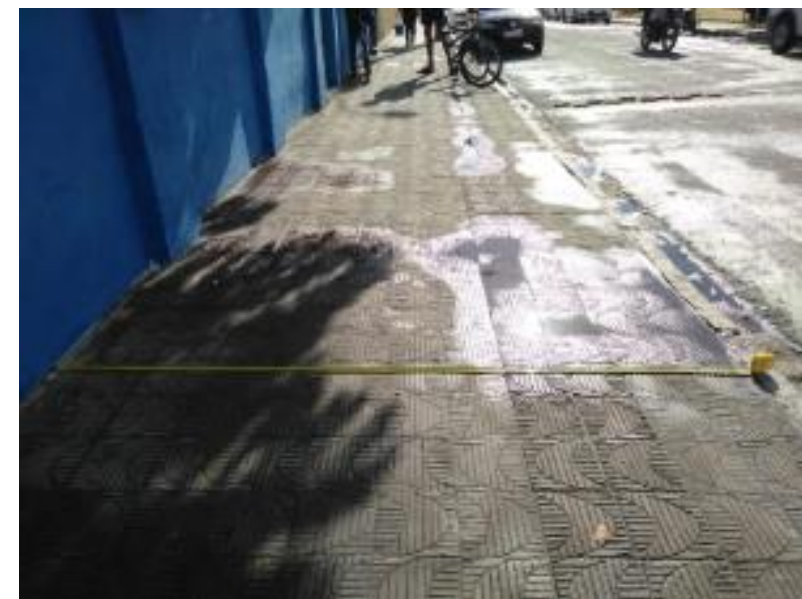

(A)



(B)

Fonte: Os Autores.

No que tange às instalações de mobiliários urbanos, estes foram empregados corretamente, pois a largura mínima do passeio não foi prejudicada. O mobiliário como postes de iluminação e lixeiras foram instalados sempre próximos ao meio-fio, sem obstruir a faixa livre, como ilustra a Figura 9 (A). A verificação dos locais de arborização é um item que não se aplica para a maioria das calçadas, devido a inexistência de árvores ou canteiros, salvo as Calçadas Norte 2, Sul 2 e Leste 1, pois se trata de uma praça (Figura 9).

Figura 9: (A) Detalhe do poste de iluminação corretamente instalado - CN2; (B) Arborização em canteiro de praça - CN4.



(A)



(B)

Fonte: Os Autores. 


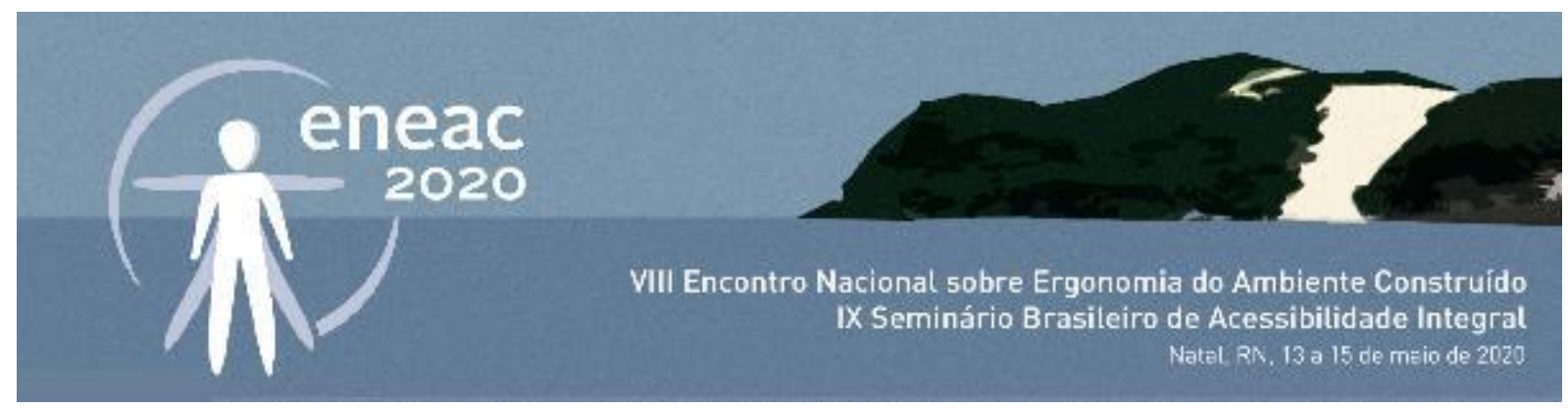

Os principais problemas de descontinuidade da calçada entre os lotes vizinhos podem ser observados na Figura 10. Na Calçada Norte 2, por exemplo, a criação de uma travessia completamente inclinada que permite o acesso de automóveis, cria um desnível acentuado. Ainda, na mesma calçada, a aplicação de diferentes materiais prejudica a locomoção dos pedestres, em decorrência dos pisos escorregadios.

Figura 10: (A) pisos desprendidos que prejudicam a continuidade; (B) Desnível acentuado prejudicando a continuidade do passeio - CN2.

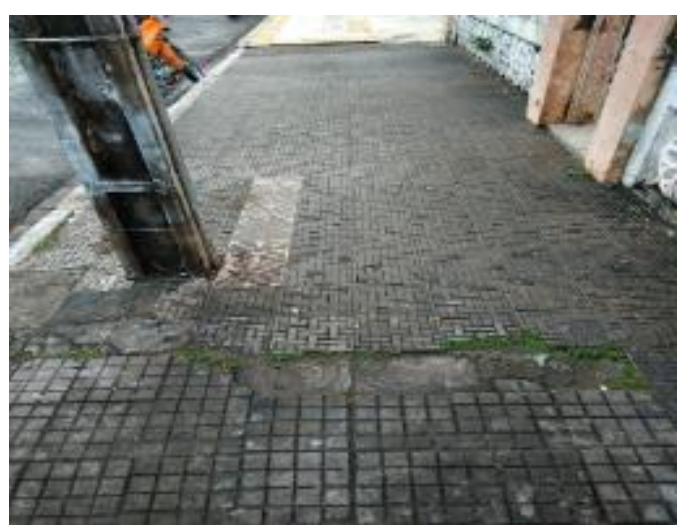

(A)



(B)

Fonte: Os Autores.

Com relação à instalação do piso tátil direcional, pode-se observar em muitos casos, sua utilização não é necessária, conforme referencial normativo. Atualmente, a norma NBR 16537 (ABNT, 2016) indica que, se durante toda a calçada houver lotes edificados, a sinalização tátil direcional pode ser dispensada. Entretanto, as Calçadas Norte 4, Sul 2 e Leste 1 apresentam trechos sem canteiro que funcionam como guia de balizamento, logo, deve-se instalar piso tátil direcional nesses trechos (Figura 11-A). No tocante à instalação do piso tátil de alerta, em praticamente todos os rebaixamentos existentes ele foi empregado inadequadamente ou não utilizado, como indica a Figura 11-B. A NBR 9050 (ABNT, 2015) indica que ao torno de elementos suspensos com altura livre entre $60 \mathrm{~cm}$ e $2,10 \mathrm{~cm}$ como orelhões, deve ser instalada uma faixa de piso tátil de alerta a $60 \mathrm{~cm}$ a partir de sua projeção, contudo postes de iluminação dispõem de alturas superiores a mencionada pela norma, logo é dispensável o uso do piso tátil de alerta. Também é dispensável o piso tátil de alerta ao longo de toda a calçada, conforme interpretação da NBR 16537 (ABNT, 2016). A instalação de piso tátil de alerta ao longo do meio-fio é um fato recorrente em várias cidades do Rio Grande do Norte, inclusive na capital, Natal.

Figura 11: (A) falta do piso tátil direcional - CN4; (B) piso tátil de alerta com utilização inadequada - CN2; (C) rampa com uso inadequado do piso tátil de alerta - CL1. 




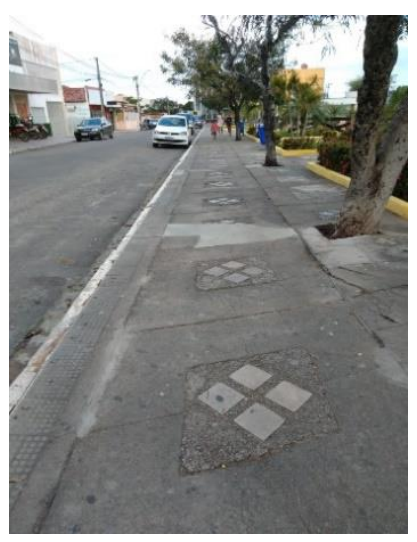

(A)

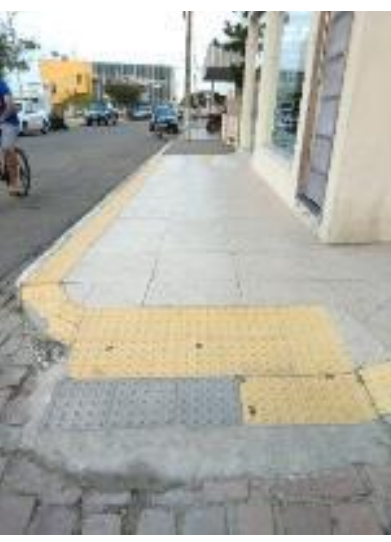

(B)

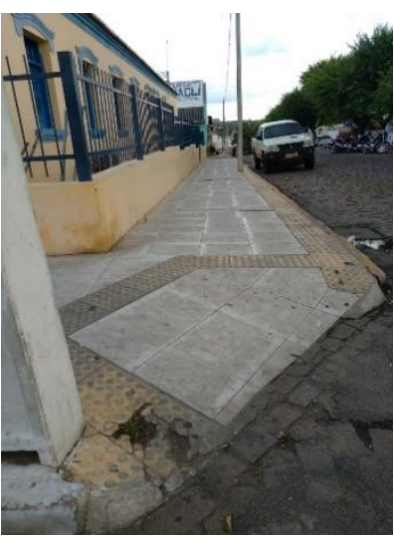

(C)

Fonte: Os Autores.

Por fim, quanto à execução de rampas para acesso de veículos, foi verificado que na grande maioria das calçadas elas não existem, pois os imóveis da área em geral não apresentam garagens. Nas situações nas quais se identificaram rampas para automóveis, elas não atenderam ao referencial normativo. Em alguns casos foram construídas fora da calçada e em outros, dentro da calçada obstruindo a faixa livre.

Figura 12: Acessos para veículos invadindo a via na Calçada Sul 1.

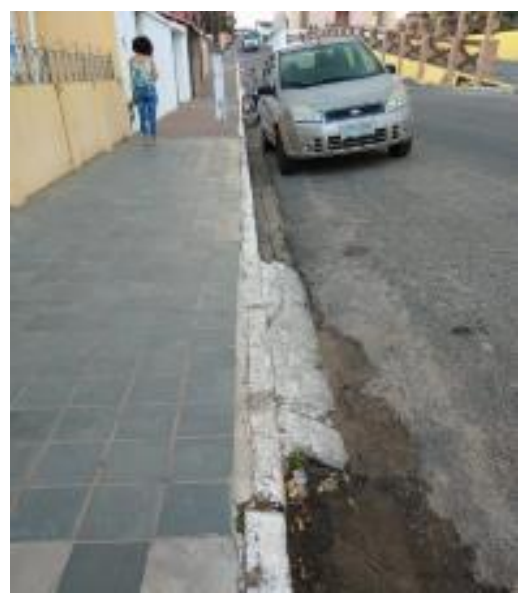

(A)

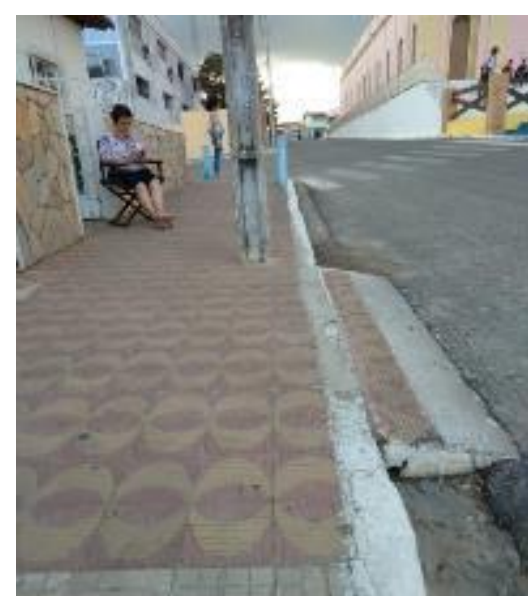

(B)

Fonte: Os Autores.

Todos esses problemas dificultam o tráfego de pedestres e não atendem as normas técnicas vigentes, que apresentam os parâmetros para o projeto da infraestrutura urbana acessível.

\section{CONSIDERAÇÕES FINAIS}

A valorização dos pedestres é essencial para a vitalidade urbana, contudo as cidades brasileiras têm sofrido as consequências de uma expansão urbana com pouco ou nenhum planejamento. Resultados disso, são as precárias condições de mobilidade e a falta de padronização de elementos básicos da 




infraestrutura urbana como as calçadas. Especificamente no caso das cidades de pequeno porte, a ausência de legislação urbana, de quadro técnico para fiscalização e a responsabilidade dos proprietários executarem e manterem suas calçadas, contribuem para a existência de problemas.

Neste estudo realizado na cidade de São Paulo do Potengi, verificou-se que os problemas que mais comprometem as condições de acessibilidade nas calçadas estão ligados ao tipo de pavimentação utilizado, à ausência ou instalação inadequada de piso tátil de alerta, à conservação e à ausência de rebaixamentos de calçadas.

Verificou-se, também, que existem tentativas de tornar o local mais acessível, com a construção de rampas de acesso, todavia são executadas sem levar em conta os princípios de acessibilidade das normas técnicas brasileiras.

Diante das avaliações realizadas, conclui-se que a área estudada não possui calçadas acessíveis, pois todas as calçadas apresentaram não conformidades em algum dos parâmetros verificados. Para reverter esta situação, faz-se necessário maior envolvimento da população, como também do poder público e de profissionais da área, buscando a execução correta e investimentos necessários. Muitos dos problemas identificados também podem ser solucionados com ações pontuais dos proprietários de imóveis da área, com a realização de manutenção, reposição de peças da pavimentação e ajustes nos níveis das calçadas.

A ausência de calçadas acessíveis compromete a circulação segura e autônoma de pessoas com deficiência ou com mobilidade reduzida, mas notadamente também prejudica que outros grupos de pessoas circulam com conforto no espaço público e usufruam da cidade. Espera-se, portanto, que os resultados desta pesquisa estimulem o debate acerca das condições de acessibilidade nas cidades da região de São Paulo do Potengi, como também subsidiem futuros projetos para a melhoria do espaço público. Como continuidade deste trabalho pretende-se desenvolver um manual que demonstre soluções para os principais problemas encontrados e sirva de padronização para as calçadas do município.

\section{REFERÊNCIAS}

ABNT. NBR 16537 - Acessibilidade - Sinalização tátil no piso - Diretrizes para elaboração de projetos e instalação. Rio de Janeiro, 2016.

ABNT. NBR 9050 - Acessibilidade A Edificações, Mobiliário, Espaços e Equipamentos Urbanos. Rio de Janeiro, 2015.

BRASIL. Lei no 13146, de 6 de julho de 2015. Institui a Lei Brasileira de Inclusão da Pessoa com Deficiência (Estatuto da Pessoa com Deficiência). Brasília, Disponível em: <http://www.planalto.gov.br/ccivil_03/_ato20152018/2015/lei/l13146.htm>. Acesso em: 22 ago. 2018.

CALDEIRA, Caldeira Boavida Miguel; SILVA, Neuza Clariana; NUNES, Flávio Paulo Jorge. Turismo acessível em Guimarães. Oportunidade e desafio para uma cidade inclusiva. Holos, [s.I.], v. 4, p.341-356, 19 set. 2017. Instituto Federal de Educação, Ciência e Tecnologia do Rio Grande do Norte (IFRN). http://dx.doi.org/10.15628/holos.2017.5274.

GEHL, Jan. Cidades para pessoas. 3. ed. São Paulo: Perspectiva, 2015.

GUIMARÃES, Rafaella Oliveira; CUNHA, Ananda Helena Nunes; SANTOS, Benjamim Jorge Rodrigues dos. Verificação da acessibilidade nas calçadas do setor central de Goiânia, GO. Multi-science Journal, Urutai, v. 2, n. 1, p.83-91, 06 maio 2015.

IBGE. Censo 2010. 2010. Disponível em: <https://censo2010.ibge.gov.br/>. Acesso em: 04 fev. 2019. 


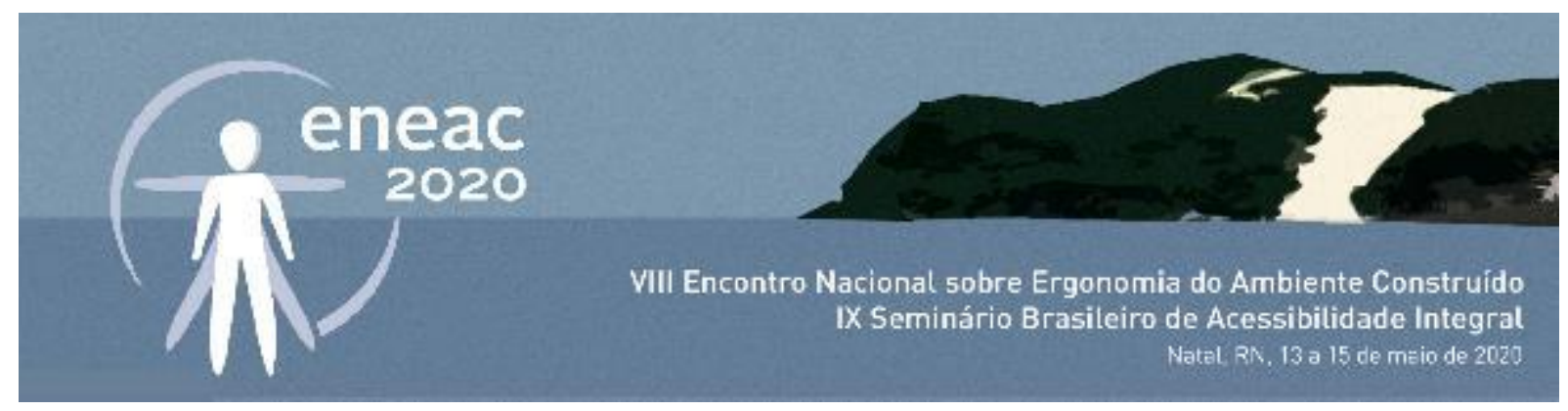

Meotti, A., Tarouco, F., \& Tonetto, L. (2019). Design ativo aplicado à experiência dos pedestres com calçadas. Risco Revista De Pesquisa Em Arquitetura E Urbanismo (Online), 17(3), 176-200. Recuperado de https://www.revistas.usp.br/risco/article/view/150785 